\title{
Pedagogical Strategy to Improve Qualification Alignment of Students to the Demands of Potential Employers
}

Judi Billups, mjbillups@salisbury.edu

Paula T. Morris,ptmorris@salisbury.edu

\begin{abstract}
Introduction. Choosing the correct person for the job can be a daunting task at any level but especially when selecting entry-level employees. In a seminal piece, Dubinsky, Howell, and Ingram (1986) investigated the idea of congruence between recruits' skills and the firm's demands. The results indicated that if the two are incongruent, the recruit's subsequent job performance may be less than adequate possibly influencing the employee to leave the firm. Replacing employees results in additional costs and use of resources that could be avoided if the incongruences in the recruitment process are resolved at the outset. Therefore, the recruitment process is a pivotal component of the firm's overall success.
\end{abstract}

Weilbaker and Merritt (1992) examined the differences between the job attributes that recruiters thought were important and the aspects recruits thought were important. Results indicate significant differences between the importance ratings of recruits and recruiters indicating a need to bridge the gap between the two. Wiles and Spiro (2004) replicated the study and confirmed the misalignment remained. By improving the alignment of the attributes recruiters think are important with the attributes potential entry-level employees think are important, progress can be made to bridge the gap between the two (p. 49).

The purpose of this study is to explore one pedagogical strategy that will improve this alignment between recruiters and potential entry-level employees. To facilitate this alignment, undergraduate students were offered skill building projects designed to help them develop qualifications that recruiters are seeking. The project entitled Create Your Own Adventure (CYOA) allowed students to propose, design, complete, and reflect upon the project of their choice. The goal of the project was to provide students with tools they can use to identify qualifications employers require and a format with which they can then acquire those qualifications thereby facilitating alignment.

Researchers and practitioners alike can benefit from the use of CYOA projects in college classrooms. In a recent Gallup-Purdue Index, interviews were conducted with over 30,000 US graduates who identified six elements of their college experience that enhanced their success in their careers. The elements included having 1) a professor that cared, 2) a professor that made you excited to learn, 3) a professor who encouraged you to pursue your dreams, 4) an internship/job in which classroom learning could be applied, 5) active involvement in extracurricular activities and organizations, and 6) semester-long projects (luminafoundation.org).

Study Overview. Undergraduate students (juniors/seniors) from a local university who were preparing to begin their professional job search were selected for the study. Students researched potential career opportunities to identify qualifications employers were seeking and then customized their project to learn the skill needed in the CYOA project. The project lasted the entire semester and progressed through the following steps: project proposal (draft/final), deliverables (blog, infographic, project completion), and self-reflection.

Utilizing a 3-way evaluation process, the CYOA included assessments from the professor, self-reflection, and peer evaluation. In an attempt to create an environment similar to the workplace, once students finalized their proposal, the project became completely student driven with optional feedback. Responsible for their success or failure, students created their goals and schedules. Many students found this independence the most challenging part of the assignment. Some asked for (and needed) a lot of feedback, others needed more than they sought, and a few excelled with no additional support.

The instructor made feedback available in a variety of ways. Sharing documents in the Google folder and sending an e-mail to the instructor triggered feedback. The instructor set aside some class time for peer sharing and 
instructor feedback. Additionally, students had access to office hours for one-on-one discussions.

Results. Sixty-one students completed the projects. Fifty-one completed individual projects and ten students paired up to complete the final 5. Results are summarized in the table below.

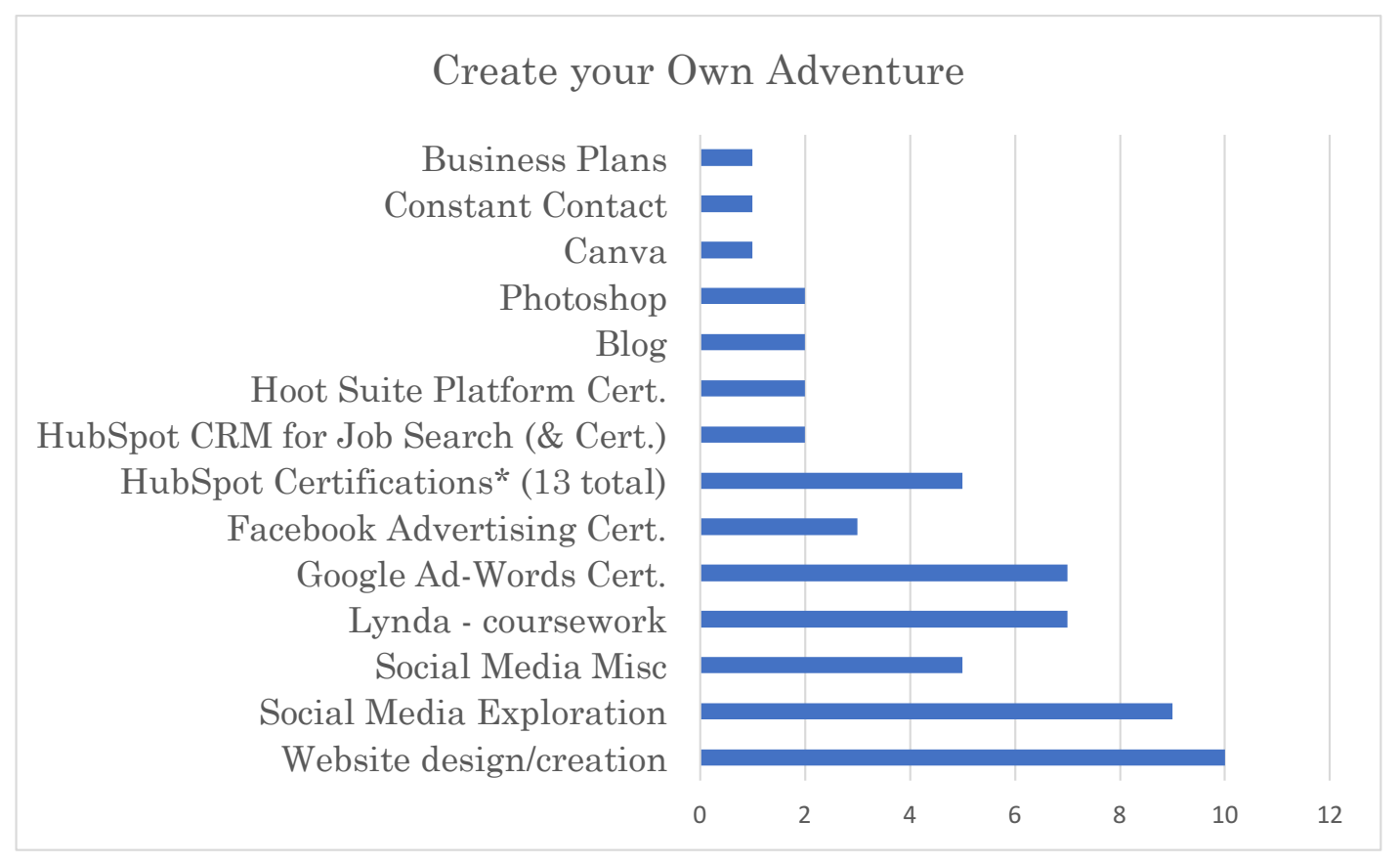

Although only five students initially proposed a HubSpot Certification, four completed additional coursework resulting in the following certifications: CRM (5), E-mail Marketing (4), Content (2), and Sales (2). The miscellaneous Social Media projects included sentiment analysis, an Instagram contest, influencer research, and LinkedIn exploration. Lynda coursework included Excel, SEO and Digital Marketing.

The CYOA project met all six of the elements identified by the Gallup-Purdue Index mentioned earlier because the instructor 1) cared about the students personally, 2) made the students excited to learn, 3) encouraged students to pursue their dreams, 4) provided internship/job opportunities to students, 5) encouraged student extracurricular involvement and 6) the project lasted all semester. Meeting at least three of these elements doubled the odds of employees being engaged at work however, the CYOA project fulfills all six elements (luminafoundation.org).

Of the 57 projects, 48 achieved or exceeded their proposed outcome while eight were close to completion. One student failed. As for the deliverables, one student turned in a blog late, and 4 had missing or late infographics. These students accounted for most of the $\mathrm{C}$ grades. The average grade for the deliverable portion of the assignment was $86.6 \%$. Selected self-reflections are noted below as the final assessment.

\section{"I thought this was a great assignment. I learned a great new skill."}

"This project motivated me to take a graphic design class next year to broaden my knowledge on using the computer in the marketing world."

Discussion. The goal of this study was to investigate one pedagogical strategy to improve alignment between recruiters and potential entry-level employees possess. The CYOA project allowed undergraduates to research a potential employer's requirements and customize a course-long project enabling them to gain that qualification. The results indicate that the project was meaningful and valuable to the students as they reported in the selfreflections. They developed a new qualification specific to a potential employer thereby improving alignment. 
As research continues to indicate misalignment of recruiters and potential entry-level employees (Dubinsky, et al., 1986; Weilbaker \& Merritt, 1992; Wiles \& Spiro, 2004), this project may be an initial broad stroke attempt to bridge the gap. Future modifications to the project can help students narrow down the focus to more specifically target the skills desired by employers to increase their marketability upon graduation. In conclusion, this study is an example of one pedagogical strategy to improve the alignment of the qualifications sought by recruiters and those possessed by undergraduates thereby, contributing to this emerging body of literature.

\section{References:}

Dubinsky, A. J., Howell, R. D., Ingram, T. N., \& Bellenger, D. N. (1986). Salesforce Socialization. Journal of Marketing, 50(4), 192-207.

Lumina Foundation. (2017) 2014 Gallup-Purdue Index Report. [Online] Available from https://www. luminafoundation.org/ [Assessed on May 29, 2017]

Weilbaker, D. C., \& Merritt, N. J. (1992). Attracting Graduates to Sales Positions: The role of recruiter knowledge. Journal of Personal Selling and Sales Management, 12(4), 49-58.).

Wiles, M. A., \& Spiro, R. L. (2004). Attracting graduates to sales positions and the role of recruiter knowledge: A reexamination. Journal of Personal Selling \& Sales Management, 24(1), 39-48.

Keywords: Employment gap, recruitment, job skills, pedagogy, classroom project

Relevance to Marketing Educators, Researchers and Practitioners: Bridging the gap between skills potential employers are seeking and skills graduates possess is relevant to Marketing Educators as they constantly search for strategies to improve the professional preparation they provide their undergraduate students. This research addresses this gap by providing one pedagogical strategy for use by educators. Researchers and Practitioners alike can benefit from and build on this research by continuing to search for and study additional strategies that may continue to bridge and eventually close the gap between skills sought and those possessed by students.

\section{Author Information:}

M. Judith Billups (DBA., Kennesaw State University), Assistant Professor of Marketing, Perdue School of Business, Salisbury University, Salisbury, MD mjbillups@salisbury.edu

Paula T. Morris (MBA., George Washington University), Professor of the Practice of Marketing, Perdue School of Business, Salisbury University, Salisbury, MD ptmorris@salisbury.edu

\section{TRACK: Marketing Education}

